Cad. Líng. Lit. Hebr., n. 15, p. 62-75, 2017

\title{
MEDICINA E LITERATURA: A PROFISSÃO E O "OFÍCIO"
}

\section{MEDICINE AND LITERATURE: PROFESSION AND “CRAFT"}

\section{Lincoln Amaral*}

\section{Resumo}

Neste artigo pretende-se destacar algumas ambivalências observadas na biografia de Moacyr Scliar como frutos de eventuais dualidades que, com base em tradições religiosas que influenciaram a cultura clássica ocidental, poderiam ser consideradas "opostas" entre si, numa interpretação corrente. Todavia, é nosso objetivo discutir que no imaginário criativo de Scliar pulsa outro olho, que afeta a visão dos olhos exteriores, amplificando-os para dar voz às ambiguidades resultantes das hibridizações culturais.

Palavras-chaves: Identidade, Alteridade, Pertença, Scliar, Judaísmo.

\begin{abstract}
In this study we intend to highlight some ambivalences observed in the biography of Moacyr Scliar as fruits of eventual dualities that, based on religious traditions that influenced the western classical culture, could be considered "opposite" to each other in a current interpretation. However, it is our aim to argue that in the creative imagination of Scliar it strikes other eye which affects the vision of the outer eyes, amplifying it to give voice to the ambiguities resulting from the cultural hybridizations.
\end{abstract}

\footnotetext{
* Lincoln Amaral é docente do Instituto Federal de Educação, Ciência e Tecnologia de São Paulo (IFSP), Campus São João da Boa Vista, e doutorando em Estudos Judaicos no Departamento de Línguas Orientais da Faculdade de Filosofia, Letras e Ciências Humanas da Universidade de São Paulo.
} 
AmARAL, Lincoln. Medicina e Literatura: A Profissão e o "Oficio"

Keywords: Identity, Otherness, Belonging, Scliar, Judaism. 
Cad. Líng. Lit. Hebr., n. 15, p. 62-75, 2017

A ciência se fala, a literatura se escreve; uma é conduzida pela voz, a outra acompanha a mão; não é o mesmo corpo, e portanto o mesmo desejo, que está por trás de uma e de outra

Roland Barthes, Da ciência à literatura.

Mas fale dentro de mim o mágico, o pequeno mágico que vocês viram numa foto anterior não com uma planta chamada serpilho, mas com um frasco de penicilina vazio; fale aquele que andou nas sombras do Vale da Morte, e vocês ouvirão - o quê? uma voz discordante, vocês ouvirão uma ardente confissão de fé na magia e no mistério Moacyr Scliar, Aprendendo a amar e a curar.

Membro ativo do Círculo Literário do Grêmio Estudantil, oscilando entre as primeiras aventuras amorosas e outras experiências inerentes ao amplo leque de descobertas adolescentes, durante o período em que permaneceu no colégio público Júlio de Castilhos, Moacyr Scliar sempre manteve uma rotina paralela de leituras vorazes, ensaiando também, de forma cada vez mais sistemática, os seus próprios prototextos. Lia de tudo, e, aos poucos, sua atração natural pelo gênero infantojuvenil deu lugar ao interesse pela literatura destinada ao público mais maduro.

Mais tarde, referindo-se à juventude, o escritor relataria seu deslumbramento com a descoberta do realismo fantástico e poria em relevo a forte influência que recebeu, dentre outros autores, de Franz Kafka, Julio Cortázar e Gabriel García Márquez. Tais fontes 
possibilitaram a ele "infinitas maneiras de repensar a sociedade mas, também [...] que a deformação do real é um poderoso instrumento para repensar a sua específica condição judaica” (ASSIS BRASIL, 2004, p. 18).

Após a conclusão do curso científico, no ano de 1955, Scliar ingressa na Faculdade de Medicina da Universidade Federal do Rio Grande do Sul, em Porto Alegre. Conciliando a atividade literária que desenvolvia nas raras "horas livres" e quaisquer "frestas" que encontrasse nos intervalos da pesada carga horária de aulas, plantões e clínicas, ele publica contos, crônicas e artigos em $O$ Bisturi, revista do Centro Acadêmico da faculdade, e outros periódicos alternativos da cidade.

Uma experiência que marcaria sua juventude e viria a refletir em suas carreiras médica e literária foi sua adesão às revoluções heroicas e quedas trágicas características das utopias políticas do Século XX. Vivia-se, então, o auge da Guerra Fria, o maniqueísmo sectário imperava, e o mundo se dividia em dois blocos ideológicos antagônicos. Ainda na universidade, ele militou no movimento juvenil sionista, de orientação socialista.

Enquanto isso, no bairro Bom Fim, a comunidade judaica parecia estar cindida entre dois projetos que poderiam conflitar-se: fazer a América ou transformar a sociedade. Apesar da exceção cubana, outros países do Novo Mundo resistiam às revoluções políticas ${ }^{1}$.

Saltamos para o ano de 1962, às vésperas do golpe militar de $1964^{2}$, em que Scliar se forma médico e publica seu primeiro livro: Histórias de Médico em Formação, que reúne crônicas do período em que ele fez estágio na Santa Casa de Misericórdia.

\footnotetext{
${ }^{1}$ No trecho a seguir, Scliar se refere aos familiares que se engajaram na opção esquerdista: "Não foram poucos os judeus que, no Brasil, militaram no Partido Comunista, pagando às vezes um alto preço por seu engajamento. Na minha família havia muitos esquerdistas. Meu tio Henrique Scliar, por exemplo. Ele era anarquista, mas estas sutilezas eu não conhecia então: para mim, era comunista. Seu filho, Carlos Scliar, era membro do Partido e amigo de Jorge Amado, que muitas vezes se hospedou com Zélia Gattai na casa do tio Henrique. Meu pai, por outro lado, não parecia muito convicto. Torceu por Luís Carlos Prestes [...]. Mas não passava disto. Sua atenção estava voltada para a luta pela sobrevivência" (SCLIAR, M.; SOUZA, M. 2000, p. 45).

2 Assis Brasil, sobre esse conturbado momento político e cultural - permeado de rupturas, inovações e retrocessos - do país em geral, e do Rio Grande do Sul em particular, observa que: "Em 1962 o ambiente
} 
Cad. Líng. Lit. Hebr., n. 15, p. 62-75, 2017

Mudança de costumes, ousadia, quebra de convenções estéticas. De modo coetâneo ao caldeirão político e social que o Brasil e o mundo experimentavam nesse período, ocorreu, na década de 1960, uma revolução cultural de grandes proporções. A Literatura nacional foi tomada por movimentos inovadores, pela quebra das normas, pela "procura de uma naturalidade coloquial que vem sendo buscada desde o Modernismo dos anos 20" (CANDIDO, 1987, p. 211) $)^{3}$.

Em 1963, Scliar faz residência em Medicina Interna e trabalha no Serviço de Assistência Médica Domiciliar e de Urgência, em São Leopoldo. No ano seguinte, torna-se professor assistente da Faculdade Católica de Medicina. A carga de trabalho é crescente, e fica cada vez mais difícil e perigoso conciliar atividades laborais com a militância. Logo depois, seus amigos são perseguidos pela recém-ditadura instalada no país. Encontra refúgio na arte, trincheira que se mostra viável para combater o arbítrio. Em 1965, casa-se com Judith Oliven e exerce clínica médica no Hospital Sanatório Partenon, de Porto Alegre. Sua produção textual não diminui, intensifica-se.

político brasileiro tumultua-se a cada dia. No ano anterior ocorre o famoso fenômeno da Legalidade, um movimento de massas liderado pelo governador Leonel Brizola, e que exigia a posse de Jango Goulart na Presidência, já que os militares se opunham a isso. O movimento dá certo, mas são dias de grande balbúrdia. $\mathrm{O}$ país em peso pede as reformas de base, e Jango deixa-se levar por veleidades populistas, aderindo às reformas e aliando-se à esquerda. Comícios se sucedem, e alguns são liderados por Jango. É preciso mudar o Brasil. O Presidente, sem o saber, dá razões a seu próprio colapso. Nesse mesmo ano de 1962 acontece em Porto Alegre um fato original que marcará para sempre a nossa história literária: a editora Difusão e Cultura lança uma antologia de contos denominada Nove do Sul. Participam do livro alguns escritores que seguirão publicando: Josué Guimarães, Tânia Faillace [...]. E Moacyr, ainda na faculdade.” (ASSIS BRASIL, 2004, p. 19).

3 Particularmente a respeito desse cenário cultural brasileiro da década de 1960, Candido esclarece que: "O decênio de 1960 foi primeiro turbulento e depois terrível. A princípio, a radicalização generosa, mas desorganizada do populismo, no governo João Goulart. Em seguida, graças ao pavor da burguesia e à atuação do imperialismo, o golpe militar de 1964, que se transformou em 1968 de brutalmente opressivo em ferozmente repressivo. $\mathrm{Na}$ fase inicial, período Goulart, houve um aumento de interesse pela cultura popular e um grande esforço para exprimir as aspirações e reivindicações do povo - no teatro, no cinema, na poesia, na educação. $\mathrm{O}$ golpe não cortou tudo desde logo, mas aos poucos. E então surgiram algumas manifestações de revolta, meio caóticas, berrantes e demolidoras, como o tropicalismo. Na verdade, tratava-se de um processo transformador que teve como eixo os movimentos estudantis de 1968 e desfechou num anticonvencionalismo que ainda hoje orienta a produção cultural [...]. Mas o timbre dos anos 60 e sobretudo 70 foram as contribuições de linha experimental e renovadora, refletindo de maneira crispada, na técnica e na concepção da narrativa, esses anos de vanguarda estética e amargura política" (CANDIDO, 1987, p. 220-221). 
Algumas trajetórias de vida são marcadas pela ambivalência de valores, passíveis de hibridização em certas circunstâncias, em outras, esse amálgama inexiste. Com efeito, nesse contexto, o termo "ambivalência" se refere a valores necessariamente compostos por dois elementos distintos, que podem ou não estar em oposição binária.

A partir dessa delimitação, surgem algumas indagações. As práticas profissionais de Scliar caminhavam paralelas e eram independentes entre si, ou não? Havia uma confluência entre essas atividades? Eram díspares ou complementares? Médico e escritor, cientista e artista. Novo hibridismo? Embora, esse possível hibridismo possa ser dialeticamente também considerado velho, na perspectiva da experiência precoce acumulada por ele.

Hibridizadas ou inconciliáveis? As tantas outras ambivalências que Moacyr Scliar acumulou em sua vida, eram convergentes ou divergentes? Misto dessas duas atribuições? Praticante de basquetebol $\times$ admirador de futebol, laico $\times$ propagador de histórias bíblicas, gaúcho $\times$ admirador de Israel, socialista por convicção $\times$ capitalista por necessidade, judeu $\times$ brasileiro. Dualidades em oposição ou complementares? Misto, parte em oposição e parte complementar?

Considerando a origem grega, o termo "híbrido" vem da palavra hybris. Traduzida como "tudo que passa da medida", "descomedimento", "ultraje", "ultrapassar das fronteiras" - seu sentido original se relaciona a alguma afronta aos deuses, atitude que era invariavelmente punida. Mais modernamente, restringindo o termo a espécie humana, "híbrido" também pode se referir à mestiçagem indesejada que viola as leis naturais.

Mestiçagem essa avaliada por parâmetros culturais que, baseados em razões morais, frequentemente a depreciam. Quando ambivalências de valores se hibridizam, o produto dessa fusão deveria ser sumariamente rebaixado? Ou esse ato de julgamento, muitas vezes 
Cad. Líng. Lit. Hebr., n. 15, p. 62-75, 2017

condicionado por automatismos culturais, decorre principalmente da tradição religiosa ocidental $^{4}$, cuja base filosófica tende a antagonizar as dualidades?

Dentre as fundamentações filosóficas basilares da doutrina cristã, a Suma Teológica proposta por Tomás de Aquino no período medieval se distingue como uma das mais influentes. Douglass e Ruether, com base no trabalho desse teólogo, esclarecem algumas raízes neoplatônicas e judaicas dessa doutrina:

O Cristianismo, como herdeiro tanto do neoplatonismo clássico e judaísmo apocalíptico, combina a imagem do Deus guerreiro masculino com a exaltação do intelecto sobre o corpo [...] Todas as dualidades básicas - a alienação do corpo pela mente; a alienação do mundo objetivo pelo eu subjetivo; o retiro subjetivo do indivíduo, alienado da comunidade social; a dominação ou rejeição na natureza pelo espírito - todas elas têm raízes na herança religiosa apocalíptico-platônica do Cristianismo clássico. (DOUGLAS; RUETHER, 1974, p. 43-44, citação traduzida por ROCHA, 2016, p. 159, grifos nossos) $)^{5}$.

Todavia, Lipovetsky e Silva, discutindo o conceito tomista ${ }^{6}$ de unidade do ser, acrescenta que a dualidade corpo/espírito originária da filosofia Platônica exerceu mais influência no Novo Testamento da bíblia cristã do que o dualismo cultura/natureza de raiz judaica.

A distinção entre o ser e a essência se apresenta como uma das mais importantes dualidades em Tomás de Aquino [...]. Esse ser comum é composto de dois princípios distintos um do outro, mas não se pode considerar ser e essência como duas "coisas" que constituem em conjunto o ente, pois o ente é uma unidade que não poderia surgir de dois elementos [...]. No campo da Ética, Tomás de Aquino postula que as escolhas do homem devem se dirigir para o que é realmente bom [...]. As normas de conduta de cada um são estabelecidas com o uso da razão, que julga nossas ações segundo uma série de primeiros princípios de ordem moral. (LIPOTSKY E SILVA, 2013, p. 196)

Com efeito, princípios filosóficos referentes a dualidades que foram sintetizados pelo Cristianismo têm origem tanto Judaica quanto Platônica. Tais vertentes são fundadoras da tradição religiosa ocidental clássica. Elas apontam a tendência de identificar o dualismo

\footnotetext{
${ }^{4}$ Aqui nos referimos à tradição religiosa ocidental originária de raízes gregas, judaicas e cristãs.

${ }^{5}$ Nessa e na próxima citação estão destacadas as dualidades.

${ }^{6}$ Relativo a Tomás de Aquino.
} 
metafísico como uma dicotomia excludente entre o bem e o mal. Para enxergar a criação artística de Scliar em toda a sua abrangência, é necessário abdicar do maniqueísmo.

Preciso, racional e técnico nos artigos médicos que redige no início da carreira, esse autor é o mesmo homem que professa “confissão de fé na magia e no mistério" nos textos ficcionais que cria. Mais tarde, nos livros sobre medicina, judaísmo e trajetórias biográficas que concebe na maturidade parece ter havido a fusão de seu olho "objetivo" ao "subjetivo".

Em busca de uma visão que vá além dos automatismos culturais, poderíamos pensar que o olho científico de Moacyr Scliar que regula o foco da lente objetiva do microscópio para descrever, em detalhes morfológicos, organelas celulares e lâminas histológicas, é, simultaneamente, aquele "olho arguto" do escritor que perscruta na calada da noite o protoplasma viscoso da subjetividade.

Seria mais adequado tratá-lo por olho sobressalente, aquele que não é a simples soma cartesiana ou exclusão recíproca dos outros dois. Mais complexo, extrapola convenções culturais, sobrepuja fronteiras formais e confere ambiguidade aos discursos. Inaugura o surpreendente olhar híbrido, caldeado por dualidade aparentemente antagônica. Amplia visão estereotipada, enxerga horizonte mais amplo, despido do limitante cabresto que não vê a margem ${ }^{7}$.

De forma enigmática, em um de seus escritos que procura aproximações entre o exercício da medicina e o da literatura, Scliar identifica o primeiro como "profissão” (médico) e o segundo como "ofício" (escritor). Apesar das divergências geradas pelo caráter

\footnotetext{
${ }^{7}$ Barthes, ao especular sobre características epistemológicas da ciência e da literatura, aponta que as duas, na sua concepção "moderna", são discursos que se diferenciam basicamente pela linguagem: "Para a ciência, a linguagem não passa de um instrumento, que se quer tornar tão transparente, tão neutro quanto possível [...] que, ao que se diz, existe fora dela e a precede: há por um lado e primeiro os conteúdos da mensagem científica, que são tudo; por outro lado e depois, a forma verbal encarregada de exprimir esses conteúdos, que não é nada. Não é uma coincidência se, a partir do século XVI, o progresso conjugado do empirismo, do racionalismo e da evidência religiosa (com a Reforma), isto é, do espírito científico (no sentido bem amplo do termo), foi acompanhado por um retrocesso da autonomia da linguagem, doravante relegada a posição de instrumento ou de "belo estilo", quando na Idade Média a cultura humana [...] atribuía-se em repartição quase igualitária os segredos da palavra e os da natureza" (BARTHES, 1967/2004, p. 4-5).
} 
Cad. Líng. Lit. Hebr., n. 15, p. 62-75, 2017

polissêmico das palavras e das distintas interpretações etimológicas que podem ser feitas sobre as mesmas, com base em nosso objetivo analítico, limitar-nos-emos estritamente ao significado atribuído por Silva (2004, p. 168) para o vocábulo “profissão”.

De acordo com o linguista, a palavra origina-se do latim (profiteri), resultado da fusão dos termos pro $=$ à frente "dos outros" + fateri $=$ declarar (algo) "em público". Assim, a partir dessa delimitação precisa, poderíamos interpretar o significado original do vocábulo "profissão" como aquele que se refere ao ato de "declarar em público".

Definida nesses mesmos moldes e ainda segundo esse pesquisador, a palavra "ofício" também provém do latim (officium), formada pela aglutinação do sufixo ops = meios "para" + o sufixo facere $=$ realizar "algo". Com efeito, poderíamos interpretar o significado original do vocábulo "ofício" como aquele que se refere ao ato de obter "meios (para) realizar", ou como quer Silva, um tipo de "dever" que se relaciona ao trabalho.

Medicina e literatura são duas profissões (no caso da literatura, talvez seja melhor falar em "ofício" [...] que têm muita coisa em comum. Ambas têm uma abertura para o humano; ambas exigem um comprometimento muito intenso por parte de quem as pratica, e ambas valorizam a palavra, ainda que de modos diferentes: para a medicina, a palavra é um instrumento terapêutico (no caso da psicoterapia, por exemplo), para a literatura, a chave da criação estética. Não é de admirar, pois, que haja um grande número de médicos escritores; Guimarães Rosa e Dyonelio Machado, por exemplo [...]. Minha vivência como médico influenciou fortemente meu trabalho literário. A experiência da doença, do sofrimento, da morte mudou radicalmente minha visão de mundo. De outra parte, meu trabalho como sanitarista revelou-me uma realidade social que eu, egresso de uma família de classe média, não conhecia (SCLIAR, 2003, p. 5).

O médico influenciando o escritor e vice-versa? É preciso relacionar a origem etimológica dos termos profissão e dever com o texto anteriormente citado. Com efeito, essa digressão nos aponta a seguinte conclusão: medicina é profissão que se "declara em público"; ao passo que literatura é ofício convertido em “dever". Uma não se sobrepõe à outra, mas eventualmente se mesclam numa nova forma de discurso híbrido. 
Tal relação pode adquirir caráter emblemático quando nos reportamos à trajetória do médico/escritor Moacyr Scliar. Lembremo-nos de que frente a tantas dificuldades econômicas, aos cerceamentos sociais, aos difíceis processos de aculturação, às restrições religiosas e a longa saga de êxodos e perseguições enfrentadas no seu histórico familiar, exercer a medicina era algo que deveria ser "declarado em público" com muito orgulho e a plenos pulmões.

"Profissão" que representa uma expressiva vitória, conquistada com grandes esforços, acena para a possibilidade de independência financeira, por meio de trabalho estável e "portável”. Sendo este um recurso muito útil em caso de exílio imprevisto, eventualidade para a qual muitos judeus aprenderam a se preparar. Sob a perspectiva de ser respeitado pelos compatriotas, inserem-se no mundo do trabalho através de um fazer valorizado e essencial a qualquer tipo de sociedade.

Porém, apesar de a medicina se "declarar em público" com todas essas vantagens, ela também mobiliza utopias íntimas, podendo se converter em instrumento de transformação política. Scliar engaja-se na medicina de caráter social-comunitário, graduando-se como sanitarista. Ele viria a dizer que essa adesão decorreu em parte de suas inquietações ideológicas estudantis e foi inspirada nas figuras antológicas de Oswaldo Cruz - pela sua revolucionária ação profilática no Brasil - e de Noel Nutels, que se distinguiu ao trabalhar com as comunidades indígenas.

O escritor irá explorar, de forma recorrente, essas personalidades em alguns livros ensaísticos sobre medicina e nos romances históricos Sonhos Tropicais (1992) - no qual a vida e obra de Oswaldo Cruz é dissecada - e A majestade do Xingu (1997) - que se baseia na trajetória de Noel Nutels ${ }^{8}$.

\footnotetext{
${ }^{8}$ Em texto não ficcional, sobre suas inquietações estudantis e a personalidade de Oswaldo Cruz, Scliar escreve: "Eu tinha clara consciência de que pouco podia fazer por eles; a diarreia de uma criança repetia-se duas, três,
} 
Cad. Líng. Lit. Hebr., n. 15, p. 62-75, 2017

Já o fazer literário de Moacyr Scliar se banha em águas mais turvas. É o “dever” obsessivo que concretiza seu desejo criativo, transgride pela arte as limitações castradoras da cultura pasteurizada por rótulos e estigmas. Alia o antigo ao moderno, o drama ao humor, a melancolia à esperança, o estrangeiro ao nacional, o científico ao poético.

Nasce do imperativo apelo (ou seria dever?) de resgatar a memória e, simultaneamente, (re) descobrir um Brasil não retratado nos manuais oficiais de historiografia. Com seu olhar híbrido, ele revela facetas originais dessa mestiçagem que nos constitui a todos. Mestiçagem tão recalcada, tão bela9.

Retornando ao depoimento em que Scliar discute sua dupla atividade laboral, inconscientemente ou não, ele deixa um hiato de significação maior à palavra "ofício". A sensação é de ausência, parece que ficou faltando algum elemento semântico complementar. Talvez, aqui caiba enfatizar a eloquência contida nesse silêncio (proposital?) ou omissão.

Num caso ou no outro, convém perscrutar as entrelinhas do discurso que insistem em se manter caladas, mas, paradoxalmente, também sonoras. "À sombra da palavra", no mesmo sentido como Waldman se refere à "retórica do silêncio" nos textos de Clarice Lispector,

quatro vezes, até o óbito pela desidratação. Ocorria-me que a solução do problema teria de ser coletiva; comecei a ir à rádio da cidade fazendo um rudimentar trabalho de educação para a saúde. Mas isso era pouco, eu sabia, muito pouco. Na vida de todo médico (ou, no caso, doutorando) chega um momento em que ele anseia por uma ação mais abrangente, não limitada à cabeceira do leito. O que lembra, a todo médico brasileiro, a figura de Oswaldo Cruz [...]. A trajetória de Oswaldo Cruz não é inusitada. Seu olhar antes restrito ao campo do microscópio, alarga-se para abranger toda a sociedade. Neste processo, que conduz do médico ao administrativo e depois ao político, a firme disciplina de início aplicada ao trabalho de pesquisa é transportada para o âmbito de engenharia social. Pouco importa se a batalha é travada contra micróbios ou amotinados; as doenças do corpo social têm de ser curadas. Neste alargamento de visão, o que se perde em profundidade, ganha-se em superfície; o especialista torna-se cada vez mais generalista, o científico é substituído pelo empírico e até pelo mágico do carisma; o rigor dá lugar à flexibilidade, a versão passa a ser tão importante quanto o fato, a imagem da pessoa ou da coisa tão importante quanto a pessoa ou a coisa em si” (SCLIAR, 1987, p. 68).

${ }^{9}$ Com a síntese a seguir, Waldman revela os traços mais marcantes da produção literária do escritor: "Há dois componentes em sua obra: a expressão de uma identidade étnica, e a manifestação de um modo de sentir e pensar nacional. Scliar situa-se fora e dentro de seu grupo, adota como tema a condição daquele que é diferente, identifica-se com ele, mas escreve na língua hegemônica, inserindo-se, com seu estilo coloquial, com sua visão crítica da realidade e com o traçado de seus anti-heróis, na literatura que está se desenvolvendo no Brasil nas últimas décadas. Vivendo de dentro a experiência de hibridização cultural de que trata, a mescla de duas cosmovisões e de duas memórias coletivas tão distantes uma da outra, Moacyr Scliar é o representante mais fecundo desse encontro nas letras brasileiras contemporâneas" (WALDMAN, 2003, p. 130). 
herdeiros eles também da lei mosaica que "operou na cultura um retraimento do visível ao legível-audível":

O retraimento do visível deveu-se à proibição de representar a imagem de Deus [...]. Mas é graças a essa interdição que o judaísmo passa a ser a expressão de um olho que se fecha para que a palavra seja ouvida. Não se vê um texto, mas leem-se as letras, ou, o que dá no mesmo, "ouve-se" a errância das letras que se combinam infinitamente diante do silêncio de Deus. A meu ver, o texto de Clarice Lispector, ainda que à revelia, está concernido a essa tradição que se desenvolve a partir do silêncio, de uma ausência (WALDMAN, 2003, p. 13).

Tal propositura, eventualmente, aplica-se também em alguns textos de Scliar. Nessa possibilidade, talvez seja possível "ouvir" a palavra não registrada no papel, operação que proporciona a façanha de múltiplas ressignificações, onde o leitor se converte num elemento ativo da criação. Seria essa também uma forma de expressão caracteristicamente judaica do "olho arguto" de Scliar? Aquela que cala o discurso quando a palavra reluta em se fixar à moldura do escrito?

Como vimos diversas ambivalências observadas nesse autor (médico/escritor, judeu/brasileiro etc.) são frutos de eventuais dualidades que, com base em tradições religiosas que influenciaram a cultura clássica ocidental, poderiam, numa interpretação corrente, ser consideradas necessariamente como "opostas" entre si. Todavia, no imaginário criativo de Scliar pulsa outro tipo de olhar, que afeta a visão dos olhos exteriores, amplificando-os para dar voz às ambiguidades resultantes das hibridizações culturais.

Scliar nos confronta com a "possibilidade ou não de ser um outro", de "viver com o outro, com o estrangeiro", numa ressignificação profunda da alteridade. Com efeito, não se trata apenas de nossa aptidão em aceitar o outro, "mas de estar em seu lugar - o que equivale a pensar sobre si e a se fazer outro para si mesmo" (KRISTEVA, p. 1994, p. 20). 
Cad. Líng. Lit. Hebr., n. 15, p. 62-75, 2017

\section{Bibliografia}

ASSIS BRASIL, Luiz Antonio de. O universo nas ruas do mundo. In: ZILBERMAN, Regina; BERND, Zilá (Org.). O viajante transcultural: leituras da obra de Moacyr Scliar. Porto Alegre: EDIPUCRS, 2004, p. 13-34.

BARTHES, Roland. Da ciência à literatura. In: O rumor da língua. 2. ed. Tradução de Mario Laranjeira. São Paulo: Martins Fontes, 2004. p. 3-12. (Ensaio originalmente publicado em 1967)

CANDIDO, Antonio. A nova narrativa. In: . A educação pela noite e outros ensaios. São Paulo: Ática, 1987. p. 199-215.

DOUGLAS, Jane Dempsey; RUETHER; Rosemary Radford (Ed.). Religion and sexism: images of woman in the Jewish and Christian traditions. New York: Simon and Schuster, 1974.

KRISTEVA, Julia. Estrangeiros para nós mesmos. Tradução de Maria Carlota Carvalho Gomes. Rio de Janeiro: Rocco, 1994.

LIPOVETSKY E SILVA, Nathalia. A relevância do cristianismo para o conceito de dignidade humana: uma análise a partir do humanismo de Tomás de Aquino. PLURA: Revista de Estudos de Religião, Juiz de Fora, v. 4, n. 1, p. 185-212, jan./jun. 2013. 
Amaral, Lincoln. Medicina e Literatura: A Profissão e o "Oficio"

ROCHA, Emmanuel Ramalho de Sá. As raízes das relações de poder sobre a mulher e a natureza no cristianismo. Paralellus, Recife, v. 7, n. 14, p. 155-167, jan./abr. 2016.

SCLIAR, Moacyr. Aprendendo a amar e a curar. São Paulo: Scipione, 2003. . A majestade do Xingu. São Paulo: Companhia das Letras, 1997. . Sonhos tropicais. São Paulo: Companhia das Letras, 1992. . Cenas médicas. Porto Alegre: UFRGS, 1987.

SCLIAR, Moacyr; SOUZA, Márcio. Entre Moisés e Macunaíma: os judeus que descobriram o Brasil. Rio de Janeiro: Garamond, 2000.

SILVA, Deonísio da. De onde vêm as palavras: origens e curiosidades da língua portuguesa. 14. ed. São Paulo: A Girafa, 2004.

WALDMAN, Berta. Entre passos e rastros: presença judaica na literatura brasileira contemporânea. São Paulo: Perspectiva, 2003. 